\title{
Yaşam Tarzı Müdahalelerinin Gestasyonel Vücut Ağırlığı Kazanımı ve Gebelik Komplikasyonları Üzerine Etkisi
}

\author{
Effects of Lifestyle Intervention on Gestational Body Weight Gain and Pregnancy Complications
}

\section{Yasemin Karaağaç ${ }^{1}$ Hülya Yardımcı²}

Geliş tarihi/Received: $12.02 .2020 \cdot$ Kabul tarihi/Accepted: 17.09.2020

\section{ÖZET}

Dünya’da, özellikle de doğurganlık çağındaki kadınlar arasında, obezite prevalansı artmaktadır. Gebelik öncesi fazla kilolu veya obez olan kadınlar sıklıkla Amerika Tıp Enstitüsü’nün gebeler için önerdiği vücut ağırlığı kazanımlarının üzerinde ağırlık kazanımı yaşamaktadırlar. Önerilerin üzerinde vücut ağırlığı kazanan gebeler gestasyonel diyabet, preeklampsi, eklampsi, hipertansiyon, tromboembolizm, obstetrik anestezi, sezaryen doğum, postpartum hemoraji, yara enfeksiyonları, emzirme başlangıcının gecikmesi, emzirme süresinin kısalması, postpartum vücut ağırlığı retansiyonu ve obezite gibi komplikasyonlarla karşı karşıya kalmaktadır. Aşırı gestasyonel vücut ağırlığı kazanımı yaşayan gebelerin bebekleri ise prematüre, ölü doğum, konjenital anomali, gestasyonel yaşına göre büyük bebek, makrozomi, omuz distosisi, neonatal hipoglisemi ve çocukluk çağında obezite açısından yüksek risk taşımaktadır. Literatürde diyet ve fiziksel aktiviteyi içeren yaşam tarzı müdahalelerin gestasyonel vücut ağırlığı kazanımını azalttığı ve gebelik komplikasyonları üzerinde olumlu etkilerinin olduğu ile ilgili çalışmalar bulunmaktadır. Sağlık bakım sistemlerinden düzenli olarak yararlanan gebeler, bebeklerinin sağlığı açısından yaşam tarzı değişikliklerine de daha olumlu yaklaştıkları için bu süreç yaşam tarzı ile ilgili müdahaleler için önemli bir dönemdir. Bu derlemede, gebelik döneminde yapılacak olan yaşam tarzı müdahalelerinin gestasyonel vücut ağırlı̆̆ı kazanımı ve gebelik komplikasyonları üzerine etkisinin literatüre dayalı olarak tartışılması amaçlanmıştır.

Anahtar kelimeler: Obezite, gebelik, gestasyonel vücut ağırlığı kazanımı, yaşam tarzı müdahaleleri, beslenme danışmanlı̆̆

\begin{abstract}
Obesity prevalence is increasing in the world, especially among women of reproductive age. Women who are overweight or obese before pregnancy often experience weight gain above the recommendations of the American Institute of Medicine for pregnant women. Pregnant women who experience excessive gestational weight gain face problems such as gestational diabetes, pre-eclampsia, eclampsia, hypertension, thromboembolism, obstetric anesthesia, cesarean delivery, postpartum hemorrhage, wound infections, delayed breastfeeding onset, shortened breastfeeding period, postpartum body weight retention and obesity. Babies of pregnant women experience excessive gestational weight gain have high risk in terms of premature, stillbirth, congenital anomaly, large for gestational age, macrosomia, shoulder dystocia, neonatal hypoglycemia and obesity in childhood. There are many studies in the literature that lifestyle interventions involving diet and physical activity reduce gestational weight gain and have positive effects on pregnancy complications. This process is an important period for lifestyle-related interventions, as pregnant women who regularly benefit from health care systems are more
\end{abstract}

1. İletişim/Correspondence: İzmir Katip Çelebi Üniversitesi Üniversitesi, Sağlık Bilimleri Fakültesi, Beslenme ve Diyetetik Bölümü, İzmir, Türkiye

E-posta: dyt.yaseminozen@gmail.com • ๑ https://orcid.org/0000-0002-2757-2485
2. Ankara Üniversitesi, Sağllk Bilimleri Fakültesi, Beslenme ve Diyetetik Bölümü, Ankara, Türkiye • • ำ https://orcid.org/0000-0002-2664-4176 
positive about lifestyle changes in terms of their baby's health. This review aimed to discuss the effects of lifestyle interventions during pregnancy on gestational weight gain and pregnancy complications based on literature.

Keywords: Obesity, pregnancy, gestational weight gain, lifestyle intervention, counseling

\section{GíRIŞ}

Obezite gelişmiş ülkeler başta olmak üzere dünyanın birçok ülkesinde önemli bir halk sağlığı problemi olarak görülmektedir (1). Obezite prevalansı hem dünyada hem de Türkiye'de artmakta ve özellikle kadınlar arasında daha yüksek oranda görülmektedir (1,2). Türkiye Nüfus Sağlık Araştırmasının 2013 raporuna göre, 15-49 yaş kadınlarda fazla kilolu olanlar \%55, obez olanlar \%27 iken; 2018 raporunda bu oranlar sırası ile \%59 ve \%30'a yükselmiştir (3).

Obezitenin kadınlarda, özellikle doğurganlıkçağındaki kadınlarda, daha sık görülmesinin nedenlerinin biri gebelikte kazanılan vücut ağırlığıdır (4). Gebeliğe bağlı oluşan obezite hem gebe hem de ailesi için yaşam boyu sağlıklı olmayan vücut ağırlığına yol açarak nesiller arası obezite döngüsünü devam ettirebilmektedir. Bu nedenle gebelik, özellikle ilk gebelik, kadınlarda yeni başlangıçlı veya kalıcı obezite için bir risk faktörü olarak değerlendirilmektedir (5,6). Günümüzde gebelik öncesi obezite, aşırı gestasyonel ağırlık kazanımı (GAK) ve doğum sonrası vücut ağırlığı retansiyonu halk sağlığı sorunları olarak kabul edilmektedir (4).

Gebelik hem anne hem de bebeğin sağlığını kısa ve uzun dönemde etkileyen kritik bir süreçtir. Bu süreçte gebeler bebeklerinin sağlığı açısından yaşam tarzı değişikliklerine açık oldukları için gebelik 'öğrenme dönemi’ olarak da tanımlanmaktadır (7). Amerika Jinekoloji ve Obstetrik Derneği (American College of Obstetricians and Gynecologists, ACOG), medikal ve obstetrik komplikasyonları olmayan gebelerin gestasyonun ilk 28 haftasında her dört haftada bir, 36. haftaya kadar iki haftada bir ve daha sonrasında haftalıkolarakrutin sağlıkkontrolleriniyaptırmalarını önermektedir (8). Özellikle sağlık bakım sistemleri ile düzenli ve sık olarak iletişimde olan gebeler için gebelik süreci yaşam tarzı ile ilgili değişikliklerin yapılmasında eşsiz bir firsat sunmaktadır (7,9). $\mathrm{Bu}$ derlemede, diyet ve fiziksel aktivite önerilerini içeren yaşam tarzı müdahalelerinin GAK ve gebelik komplikasyonları üzerindeki etkilerinin tartışılması amaçlanmıştır.

\section{Gestasyonel Vücut Ağırlığı Kazanımı ve Obezite}

Gebelik sürecinde annenin vücut ağırlığında meydana gelen artış, GAK olarak adlandırılmaktadır. Bu vücut ağırlığı artışı genel olarak; fetus, plasenta, uterus ve amniyotik sıvıdaki su, protein ve yağ ile birlikte annenin kan hacmi, meme bezi ve yağ dokusundan oluşmaktadır $(6,10,11)$. Gestasyonel vücut ağırlığ kazanımı doğumdan hemen önceki son prenatal görüşme ile ilk prenatal görüşme arasındaki vücut ağırlığı farkından hesaplanmaktadır (10).

Yirminci yüzyılın ilk yarısında yürütülen GAK izleme programları, günümüz önerilerinden çok daha sinırlı olmakla birlikte genellikle GAK’ı kısıtlama üzerine odaklanılmış programlardan oluşmuştur. Ancak bu politikalar, 1960-1970’lerde düşük doğum ağırlığı ve bununla ilişkili morbidite ve mortalite oranlarının artmasına yol açması nedeni ile 1990 yılında daha etkili vücut ağırlığı kazanımlarının sağlanması için öneriler değiştirilmiştir (12). Amerika Tıp Enstitüsü (Institute of Medicine; IOM) tarafindan 1990 yılında gebelik öncesi beden kütle indeksine (BKI) özel GAK önerileri yayınlamıştır (13). Bu öneriler, 2009 IOM kılavuzunda (14), hem anne hem de bebek için kısa ve uzun vadeli en iyi sağlık sonuçlarını sağlamak amacı ile güncellenmiştir (Tablo 1). Ancak, IOM kılavuzunda obezite derecelendirmelerine, irk ve etnik kökenlere veya adölesanlar gibi özel gruplara özgü farklı GAK önerileri bulunmamaktadır (10).

Gebelik öncesinde fazla kilolu olan kadınlar için önerilen GAK, 1990 yılında yayınlanan kılavuzda 
Tablo 1. Gebelik öncesi BKİye göre önerilen gestasyonel vücut ağırlığı kazanımları

\begin{tabular}{lll}
\hline Gebelik öncesi BKİ & & Önerilen vücut ağırlığı kazanımı (kg) \\
\hline $\mathrm{BKI} \dot{\mathrm{I}}<18.5 \mathrm{~kg} / \mathrm{m}^{2}$ & Zayıf & $12.5-18$ \\
$\mathrm{BKI}=18.5-24.9 \mathrm{~kg} / \mathrm{m}^{2}$ & Normal & $11.5-16$ \\
$\mathrm{BKI}=25.0-29.9 \mathrm{~kg} / \mathrm{m}^{2}$ & Fazla kilolu & $7-11.5$ \\
$\mathrm{BKI} \dot{\mathrm{I}} \geq 30 \mathrm{~kg} / \mathrm{m}^{2}$ & Obez & $5-9$
\end{tabular}

BKI: Beden kütle indeksi, kg: Kilogram, m:Metre

6.8-11.3 kg iken obezler için önerilen GAK'ın alt sınırı $6.8 \mathrm{~kg}$ olarak belirtilmesine rağmen üst sinırı belirlenmemiştir (13). Obez gebeler için önerilen GAK, 2009 yllındaki kılavuzda ise 5-9 kg ile sınırlandırılmıştır (14). Konuya ilişkin yapılan bir meta analiz çalışmasında, 2000-2009 yılları arasındaki GAK eğilimleri incelenmiştir. Elde edilen verilere göre, gebe kadınların \%44.4'ünün önerilen GAK üzerinde vücut ağırlığı kazandığı belirlenmiştir. Ayrıca 2002 ile 2003 yılları arasındaki obez kadınların \%46’sının, fazla kilolu kadınların ise \%63’ünün aşırı GAK yaşadığı bildirilmiştir (15).

Gebenin yeterli ve dengeli beslenmesi uygun GAK oluşmasına katkıda bulunarak fetal büyüme ve gelişiminin optimum düzeyde olmasını sağlar. Fetal programlama teorisine göre fetal beslenme, erişkin dönemdeki yaşam tarzı ile ilişkili kronik hastalıkların oluşma riski üzerinde önemli bir etkiye sahiptir. Annenin prenatal ve postnatal vücut ağırlığı kazanımının fazla olması bebeğin çocukluk çağında daha yüksek BKİ ve artmış metabolik sendrom riskine sahip olması ile ilişkilendirilmektedir (5). Bu nedenle ACOG, özellikle fazla kilolu ve obez kadınlar için gebelikten önce, gebelikte ve doğumdan sonra obeziteyi önlemek amacı ile pre-, peri- ve postnatal dönemde sıkı izlemler önermektedir. Konuya yönelik hazırlanan perinatal bakım kılavuzları'na göre, gebelere sağlık hizmeti sağlayan personel ilk prenatal görüşmede gebenin BKİsini belirlemeli, ilk görüşmeden başlayarak gebelik boyunca düzenli olarak planlanan her görüşmede uygun GAK, diyet ve egzersiz ile ilgili konuları tartışmalı, GAK önerilerine olan uyumu değerlendirmeli ve önerilen ağırlık kazanımından önemli sapmalar oluştuğunda özel olarak bireysel danışmanlık hizmeti sağlamalıdır (8).
Gebelik öncesi BKİ, IOM önerilerine uyumda en önemli belirleyici olarak görülmektedir (14). Ulusal Hayati İstatistikler Sistemi'nin verileri (16), 2015 yılında zamanında tek bebek doğuran kadınların sadece \%32'sinin GAK için önerilen vücut ağırlığında olduğunu, \%21'inin önerilenden az, \%48'inin ise önerilenden fazla vücut ağırlığı kazandığını göstermektedir. Bu verilere göre aşırı GAK, en yüksek gebelik öncesinde fazla kilolu (\%61) ve obez (\%55) olan kadınlarda görülmektedir. Kanada'nın Ontario eyaletinin sağlık verilerinde de tüm BKİ kategorilerindeki kadınlarda aşırı GAK'ın yaşanabildiği, bununla birlikte özellikle gebelik öncesinde fazla kilolu veya obez olan kadınlarda normal vücut ağırlığına sahip kadınlara göre aşırı GAK yaşama riskinin daha yüksek olduğu saptanmıştır (17). Gebelik öncesinde fazla kilolu veya obez olan kadınlar gebelik komplikasyonları açısından yüksek risk altında oldukları için bu kişilerde aşırı GAK'ın da yaşanması, komplikasyon riskini çok daha ciddi bir boyuta taşımaktadır. Bu konuda vurgulanması gereken nokta; gebelik öncesinde fazla kilolu veya obez kadınlarda görülen gebelik komplikasyonlarının aşırı vücut ağırlığı kazanımı yaşandığı takdirde zayıf ve normal vücut ağırlığı olan gebelerde de gelişebileceğidir (18).

Toplam GAK'ın oluşumunda birçok faktör etkili olmakla birlikte fiziksel aktivite ve beslenme alışkanlıkları en çok değiştirilebilir olanlardır (10). Bir Cochrane sistematik derlemesinde (19), diyetin, egzersizin veya her ikisinin birlikte uygulanmasinın aşırı GAK’ \%20 azalttığı yüksek düzeyde kanıt olarak gösterilmiştir. $\mathrm{Bu}$ nedenle gebelik öncesi, sırası ve sonrası dönemde değiştirilebilir risk faktörleri üzerinde müdahaleler planlamak kritiktir. Gebelik komplikasyonlarında oluşabilecek olan maliyetler 
de göz önüne alındığında bu müdahaleler maliyetetkinlik açısından önemli bir strateji olarak görülmektedir (20). Gebenin diyeti ile GAK arasındaki ilişkiyi inceleyen bir çalışmada, önerilere uygun GAK’ı olan gebelerin diyetleri ile karşılaştırıldığında aşırı GAK'ı olan gebelerin diyetlerinde enerjinin yağdan gelen yüzdesi daha fazla, karbonhidrattan gelen yüzdesi ise daha düşük bulunmuştur (21). Bu konuyu değerlendiren bir başka çalışmada da, 2. trimesterin sonundaki GAK alımının; enerji, protein ve hayvansal besinlerden alınan yağ ile pozitif, karbonhidrat ile negatif ilişkili olduğu saptanmıştır (22).

Gebelerin enerji ve besin ögesi gereksinimleri için diyet referans değerleri IOM tarafından 2006 yılında yayınlanmıştır, ancak bu değerler gebelerin BKI değerine göre değişmemektedir (23). Gebeler için fiziksel aktivite önerilerinde bulunan ACOG (24), medikal ve obstrektik komplikasyonları olmayan gebelere sağlıklıbir diyetile birlikte haftanın çoğugünü $\geq 30$ dk orta şiddette aerobik ve dayanıklılık egzersizleri yapmalarını önermektedir. Danışmanlık hizmeti kapsamında gebelere önerilen fiziksel aktivitenin anne açısından sağlıklı vücut ağırlığı kazanımını sağlamak, doğumu kolaylaştırmak, bel ağrısını hafifletmek, gestasyonel hipertansiyon ve sezaryen doğum riskini azaltmak, mental durumu iyileştirmek ve doğumdan sonraki süreçte toparlanmayı hızlandırmak gibi olumlu etkileri bulunmaktadır (25). Bu bağlamda yapılacak olan grup egzersizleri, gebelerin sağlıklı yaşam tarzı programlarına uyumu ve kabulünü kolaylaştırmaktadır. Hava durumu ya da saatlerin çakışması gibi nedenler ile grup egzersizlerini kaçıran gebeler için evde bireysel egzersiz yapmanın desteklenmesi de gebelerin fiziksel aktivitelerini arttırmak için etkili bir yol olabilir (26).

İlk trimesterdeki obez gebelerin katıldığı bir çalışmada (20), gebeler kontrol grubu ve müdahale grubu olarak ikiye ayrılmış ve müdahale grubu ile grup seminerleri, bireysel danışmanlıklar ve telefon görüşmeleri yapılmıştır. Çalışmanın sonunda müdahale grubundaki gebelerin GAK'larının kontrol grubundaki GAK'ların yaklaşık yarısı kadar olduğu ve aradaki bu farkın istatistiksel olarak anlamlı olduğu bildirilmiştir. Gebeliğin ikinci trimesteri ile diyetisyen tarafından düzenlenmiş kişiye özelbeslenme programı ve haftada 3-4 kez 25 dk ile başlayıp artarak devam eden yürüyüş programı müdahalelerinin başladığı bir çalışma yürütülmüştür. Müdahaleden önce aşırı vücut ağırlığı kazanımı yaşamış olan fazla kilolu ve obez gebelerde müdahaleden sonraki haftalık ve toplam vücut ağırlığı kazanımlarının sırası ile $0.38 \pm 0.2$ $\mathrm{kg}$ ve $6.8 \pm 4.1 \mathrm{~kg}$ olması ve gebelerin \%80'inin önerilen sınırlar içinde vücut ağırlığı kazanması sağlanmıştır (27). Obez gebelerin katıldığı bir diğer çalışmada ise beslenme ve fiziksel aktivite ile ilgili önerilerin olduğu eğitici broşür veya eğitici broşürle birlikte diyetisyen tarafından verilen beslenme eğitimini içeren yaşam tarzına yönelik müdahalenin beslenme alışkanlıkları, fiziksel aktivite düzeyi ve GAK üzerindeki etkileri kontrol grubu oluşturularak incelenmiştir. Kontrol grubuna kıyasla müdahale grubunda ilk trimesterden sonra yağ, özellikle doymuş yağ tüketimlerinin azaldığı, protein tüketimlerinin arttığı, ancak gruplar arasında istatistiksel olarak anlamlı bir fark olmadığı saptanmıştır. Ayrıca, müdahalenin fiziksel aktivite düzeyi ve GAK üzerinde anlamlı bir etkisi görülmemiştir (28).

Sağlıklı beslenme, fiziksel aktivite ve GAK önerilerini içeren danışmanlığın sağlandığı bir çalışmada (29), danışmanlık müdahalesi normal vücut ağırlığına sahip gebelerde aşırı GAK'da anlamlı düşüşler sağlarken, fazla kilolu gebelerde bu durumun etkili olmadığı bulunmuştur. Yüz yüze görüşme, eğitim materyallerinin haftalık olarak elektronik posta ile gönderilmesi ve telefon görüşmelerinin yapıldığı bir diğer çalışmada ise (30), müdahalelerin normal vücut ağırlığı olan gebelerde aşırı GAK yaşayan kişi sayısının kontrol grubuna göre anlamlı olarak daha az olmasını sağladığı, ancak fazla kilolu ve obez kadınlarda etkili olmadığı saptanmıştır.

Gebelikte aşırı vücut ağırlığı kazanımını azaltmaya yönelik müdahalelerin başarılı olabilmesi için zaman ve personel kullanımının fazla, eğitimlerin yoğun olduğu, beslenme ve fiziksel aktivite önerilerini içeren programlar oluşturulmalıdır. Bu müdahalelerin etkili olmasında bireylerin motive 
ve uygun olması da oldukça önemlidir (28). Gebelik öncesi normal vücut ağırlığına sahip kadınların fazla kilolu ve obez kadınlara göre sağlıklı beslenme konusunda daha bilinçli ve istekli oldukları, verilen eğitim ve danışmanlıklara olan uyumlarının da daha yüksek olduğu düşünülmektedir (26). Gebeler bazı nedenlere bağlı olarak grup etkinliklerinin hepsine katılamadıkları için, bireysel olarak düzenlenen etkinlikler yaşam tarzı değişiklikleri açısından daha faydalı olabilmektedir. Ayrıca davranış terapilerinin de yer aldığı yoğun danışmanlıklar gebelerin motivasyonunu arttırabilir (28).

\section{Aşırı Gestasyonel Vücut Ağırlığı Kazanımının Neden Olduğu Sorunlar}

Önerilere uygun GAK, anne ve bebek için optimal sağlık sonuçları ile ilişkili iken önerilenden daha az vücut ağırlığı kazanımı düşük doğum ağırlığı ve preterm doğumla ilişkilendirilmektedir. Aşırı GAK olan gebe; obezite, gestasyonel diyabet, preeklampsi, eklemsi, hipertansiyon, tromboembolizm, obstetrik anestezi, sezaryen doğum, postpartum hemoraji, yara enfeksiyonları, postpartum vücut ağırlığı retansiyonu, emzirmebaşlangıcınıngecikmesiveemzirmesüresinin kısalması gibi komplikasyonlar ile karşılaşmaktadır $(5,6,11,31)$. Gebelikteki obezite, operatif vajinal doğum ve postoperatif komplikasyonlarla da ilişkilendirilmektedir (32). Bu gebelerin bebekleri ise prematüre, ölü doğum, konjenital anomali, gestasyonel yaşına göre büyük bebek, makrozomi, omuz distosisi, neonatal hipoglisemi ve çocukluk çağında obezite açısından yüksek risk taşımaktadırlar $(5,11)$. Savitz ve arkadaşları (33), gebelikte aşırı vücut ağırlığı kazanımının; fazla kilolu ve obez kadınlarda uygun vücut ağırlığı kazanımı olanlara kıyasla preterm doğum riskini 1.4-1.7 kat; normal vücut ağırlıklı kadınlarda uygun ağırlık kazanımı olanlara kıyasla 1.3 kat arttırdığını ve aradaki farkın istatistiksel olarak anlamlı olduğunu belirtmişlerdir.

Toplam 144 gebe kadının standart bakım ve yaşam tarzı danışmanlığı almak üzere iki gruba ayrıldığı randomize kontrollü bir çalışmada (32), müdahale grubuna haftada en az üç kez orta yoğunlukta egzersiz önerisi ve diyetisyen tarafından hazırlanan beslenme programı verilmiştir. Gebeliğin sonunda müdahale grubunun daha az vücut ağırlığı kazandığı $(\mathrm{p}=0.01)$, rutin bakım alan grubun doğum sürecinde başarısızlık nedeni ile daha çok sezaryen doğum yaptığ $(p=0.02$ ) ve IOM önerilerine uymayan gebelerin bebeklerinin uyanlara göre daha fazla vücut ağırlığı ile doğduğu belirlenmiştir $(p<0.001)$. Müdahale olarak yüz yüze beslenme danışmanlığı ve telefon görüşmelerinin yapıldığı başka bir çalışmada ise (34); müdahale grubunun GAK ile ilgili diyetsel bilgi, tutum ve davranışlarında anlamlı gelişmelerin görüldüğü ve bu gruptaki uygun GAK olan gebe sayısının rutin bakım alan gruptan üç kat fazla olduğu bulunmuştur $(p<0.001)$. Müdahale grubunda yer alan gebelerde anemi ve hipertansiyon, bebeklerinde ise makrozomi ve preterm doğum morbiditesinin kontrol grubuna göre daha düşük olduğu saptanmıştır. Ayrıca ilk ziyaret veya kontrol ile karşılaştırıldığında müdahale grubundaki gebelerin peynir, sebze-meyve, balık ve kırmızı et tüketiminde ve farklı besinleri tüketme sıklığında önemli artışlar gözlemlenmiş, beslenme ile ilgili farkındalıkları \%3’ten \%31'e yükselmiştir $(\mathrm{p}=0.001)$.

Aşırı GAK'ın perinatal sağlık riskleri iyi biliniyor olmasına rağmen, sağlık üzerinde en büyük etkiye sahip olan trimesterin hangisi olduğu bilinmemektedir (5). Prospektif bir çalışmada (35), tüm trimesterlerdeki aşırı GAK’ın, gestasyonel yaşa göre küçük bebek doğma riskini azalttığı, büyük bebek doğma riskini arttırdığı bildirilmiştir. Bu çalışmada, birinci trimesterde önerilenin üstünde kazanılan her bir kilogramın, tüm BKI kategorilerinde gestasyonel yaşa bağlı doğum ağırlığında artış ile ilişkili olduğu ve toplam aşırı GAK'ın yanı sıra, gebeliğin erken döneminde yaşanan aşırı GAK'ın da doğum sonuçlarını etkilediği gösterilmiştir. Brezilya'da yapılan bir çalışma (36), ikinci trimesterde önerilenden fazla vücut ağırlığı kazanımının gestasyonel yaşa göre büyük bebek doğma riski; üçüncü trimesterde önerilenden fazla vücut ağırlığı kazanımının ise preterm ve sezaryen doğumda artış ile ilişkili olduğu saptanmıştır. Konuya ilişkin bir diğer çalışmada, 
gebeliğin ilk yarısında önerilenden fazla vücut ağırlığı kazanımı olan gebelerin bebeklerinin, uygun vücut ağırlığı kazanımı olan gebelerin bebeklerine göre anlamlı olarak daha fazla doğum ağırlığı, boy uzunluğu ve vücut yağı ile doğduğu belirlenmiştir. Gebeliğin ilk yarısında önerilenden fazla vücut ağırlığı kazanan gebelerin \%55'inde toplam GAK'ın da fazla olduğu gösterilmiştir (37). Bu çalışmalardan yola çıkarak yapılması planlanan müdahalelerin gebeliğin erken dönemlerinde başlatılması gerekliliği vurgulanmalıdir.

\section{Aşırı Gestasyonel Vücut Ağırlığı Kazanımı ve Postpartum Dönemde Vücut Ağırlığının Durumu}

Gebelikte önerilenden fazla vücut ağırlığı kazanımının postpartum ağırlık kaybının önerilenden daha az olmasına yol açtığı ve postpartum vücut ağırlığı retansiyonu ile GAK arasında pozitif yönde güçlü bir ilişkinin olduğu bildirilmektedir $\quad(r=0.89)$ (29). Postpartum vücut ağırlı̆̆ retansiyonu uzun dönemde obezite ve diğer kronik hastalıklar ile ilişkilendirilmektedir (30,35). Gebelik öncesi normal, fazla kilolu veya obez olan kadınların yanı sıra gebelik öncesi zayıf olan kadınlar da önerilenden daha fazla kazanılan vücut ağırlığı açısından risk altındadır. $\mathrm{Bu}$ nedenle önerilen aralıklar arasında GAK tüm gebe kadınlar için önem arz etmektedir (31). İlk gebeliğinde aşırı GAK olduğu için postpartum vücut ağırlığı retansiyonu fazla olan kadınlar bir sonraki gebeliklerinde daha fazla ağırlık kazanımı ve daha fazla postpartum vücut ağırlığı retansiyonu açısından risk altındadırlar (6). Postpartum vücut ağırlığı retansiyonunun azaltılmasında emzirmenin de önemli katkısı vardır. Emzirme ile ilgili kohort çalışmalarını değerlendiren bir meta-analiz çalışması (38), emzirmenin postpartum vücut ağırlığı retansiyonunu anlamlı olarak azalttığını ve bu etkinin 30 yaşın altındakilerde, ilk kez doğum yapanlarda, gebelik öncesi BKİsi normal olanlarda ve 6-12 ay emzirenlerde daha güçlü olduğunu bildirmektedir.

Birçok kadın gebelik ve gebelik sonrası besin alımlarını arttırırken egzersizlerini azaltmakta ve gebelik öncesi diyet ve egzersiz alışkanlıklarına geri dönmeyi uzun süre erteleyebilmektedir (39). Gebeliğin 16. haftası veya doğumla başlayıp postpartum 6 . aya kadar, diyet ve fiziksel aktiviteyi içeren danışmanlığın yer aldığı bir çalışmada (31), danışmanlığın gebelikle birlikte başladığı grupta; GAK, postpartum vücut ağırlığı retansiyonu $\geq 5 \mathrm{~kg}$ olan kişi sayısı diğer gruplara göre anlamlı olarak daha düşük bulunmuştur. Dolayısı ile gebelik sırasında başlanan danışmanlığın doğum sonrası başlanan danışmanlığa veya gebelere rutinde verilen danışmanlığa göre, postpartum vücut ağırlığı kazanımının önlenmesinde daha etkili olduğu belirtilmektedir. Bir diğer çalışmada da; yüz yüze görüşme, eğitim materyallerinin haftalık olarak elektronik posta ile gönderilmesi ve telefon görüşmeleri kontrol grubuna göre anlamlı olarak daha fazla sayıda kadının, postpartum 6. ayda, gebelik öncesi vücut ağırlığına veya daha azına geri dönmesini sağlamıştır (30).

\section{SONUÇ VE ÖNERİLER}

Doğurganlık çağındaki kadınlarda obezite prevalansı hızla artmakta ve özellikle gebelik öncesi obez olan kadınlarda, gebelikle birlikte sıklıkla aşırı ağırlık kazanımı yaşanmaktadır. Aşırı GAK, hem anne hem de bebeğin sağlığını kısa ve uzun dönemde olumsuz yönde etkilemekte ve obezite prevalansının artmasına yol açmaktadır. Literatürdeki çalışmalar incelendiğinde gebelikte uygulanan yaşam tarzı müdahalelerinin GAK'ı ve gebelik komplikasyonlarını azaltmada olumlu etkilerinin olduğu görülmektedir. $\mathrm{Bu}$ yaşam tarzı müdahalelerinin mümkünse gebelik öncesinden başlatılması, gebelik ve postpartum dönemde devam ettirilmesi global epidemi olan obezite ve obezite ile ilişkili morbidite ve mortalite oranlarının azaltılmasında önemli bir katkı sağlayacaktır.

Yaşam tarzı müdahaleleri multidisipliner bir takımın güçlü yanlarını kullanmalı; uygun bir beslenme programı, fiziksel aktivite ve emzirme danışmanlığını içermelidir. Gebelerin beslenme durumunu değerlendirmek, beslenme ve emzirme danışmanlığı yapmak, sosyal destek ve fiziksel aktivite önerileri 
sağlamak için diyetisyenler multidisipliner ekipte yer almalıdır. Diyetisyen, gebenin gebelik öncesi beslenme alışkanlıklarını öğrenmeli ve gebelik öncesi BKİye dayanan bir beslenme planı oluşturarak gebenin önerilen vücut ağırlığı kazanımı sınırları içinde kalabilmesini sağlamalıdır. Ayrıca postpartum dönemde de vücut ağırlığı kaybı ve emzirme konularında danışmanlık sağlayarak annelere destek olmalıdır. Gebelik öncesinde, sırasında ve sonrasında multidisipliner takımın bir parçası olarak diyetisyenlere daha fazla erişim sağlanması ve Aile Hekimliği Merkezleri'nde yer alması soruna yönelik çözümlerin üretilmesi açısından önemlidir.

Çıkar çatışması - Conflict of interest: Yazarlar çıkar çatışması olmadığını beyan ederler. - The authors declare that they have no conflict of interest.

\section{KAYNAKLAR}

1. World Health Organization. WHO fact sheet on overweight and obesity. Updated April 2020. Available at: https://www.who.int/news-room/fact-sheets/detail/ obesity-and-overweight. Accessed June 28, 2020.

2. Türkiye Endokrinoloji ve Metabolizma Derneği. Obezite tanı ve tedavi kılavuzu. Ankara: BAYT; 2019. 18 p.

3. Hacettepe Üniversitesi Nüfus Etütleri Enstitüsü. 2018 Türkiye Nüfus ve Sağlık Araştırması. Hacettepe Üniversitesi Nüfus Etütleri Enstitüsü, T.C. Cumhurbaşkanlığı Strateji ve Bütçe Başkanlığı ve TUBİTAK. Ankara, Türkiye.

4. Farpour-Lambert NJ, Ells LJ, Martinez de Tejada B, Scott C. Obesity and weight gain in pregnancy and postpartum: an evidence review of lifestyle interventions to inform maternal and child health policies. Front Endocrinol [Internet]. 2019 March. Available at: https://www. frontiersin.org/articles/10.3389/fendo.2019.00163/full. doi:10.3389/fendo.2018.00546.

5. Campbell EE, Dworatzek P, Penava D, de Vrijer B, Gilliland JA. Factors that influence excessive gestational weight gain: Moving beyond assessment and counselling. J Matern Fetal Neonatal Med. 2016;29(21):3527-31.

6. Poston L, Caleyachetty R, Cnattingius S, Corvalán C, Uauy R, Herring S, et al. Preconceptional and maternal obesity: epidemiology and health consequences. Lancet Diabetes Endocrinol. 2016;4(12):1025-36.

7. Whitaker K, Wilcox S, Liu J, Blair S, Pate R. Patient and provider perceptions of weight gain, physical activity and nutrition counseling during pregnancy: a qualitative study. Women's Health Issues. 2016;26(1):116-22.
8. American Academy of Pediatrics, American College of Obstetricians and Gynecologists. Guidelines for perinatal care. Washington: DC; 2012.

9. Cole K, Gudzune K, Bleich S, Bennett W, Cheskin L, Henderson J, et al. Influence of the 5A's counseling strategy on weight gain during pregnancy: An observational study. Journal of Women's Health. 2017;26(10):1123-30.

10. Kominiarek M, Peaceman A. Gestational weight gain. Am J Obstet Gynecol. 2017;217(6):642-51.

11. Lim C, Mahmood T. Obesity in pregnancy. Best Pract Res Clin Obstet Gynaecol. 2015;29:309-19.

12. Abrams B, Altman SL, Pickett KE. Pregnancy weight gain: Still controversial. Am J Clin Nutr. 2000;71(5):123341.

13. Committee on Nutritional Status During Pregnancy and Lactation, Institute of Medicine. Nutrition during pregnancy. Part I: weight gain; Part II: nutrient supplements. National Academies Press; Washington, DC: 1990.

14. Institute of Medicine. Weight gain during pregnancy: reexamining the guidelines. National Academies Press; Washington: DC; 2009.

15. Johnson JL, Farr SL, Dietz PM, Sharma AJ, Barfield WD, Robbins CL. Trends in gestational weight gain: the pregnancy risk assessment monitoring system, 20002009. Am J Obstet Gynecol. 2015;212:806-21.

16. QuickStats: Gestational weight gain among women with full-term, singleton births, compared with recommendations 48 States and the District of Columbia, 2015. MMWR Morb Mortal Wkly Rep. 2016;65(40):1121. Available at: https://www.cdc.gov/mmwr/volumes/65/ $\mathrm{wr} / \mathrm{mm} 6540 \mathrm{a10}$.htm. Accessed June 28, 2020.

17. One in a Million. Born Ontario Biennial Report 20162018. Available at: https://www.bornontario.ca/en/ publications/resources/Documents/BORN-BiennialReport-2016-18.pdf. Accessed June 28, 2020.

18. Schack-Nielsen L, Michaelsen KF, Gamborg M, Mortensen EL, Sorensen TI. Gestational weight gain in relation to offspring body mass index and obesity from infancy through adulthood. Int J Obes. 2010;34:67-74.

19. Muktabhant B, Lawrie TA, Lumbiganon P, Laopaiboon M. Diet or exercise, or both, for preventing excessive weight gain in pregnancy. Cochrane Database Syst Rev. 2015;(6): CD007145. DOI: 10.1002/14651858.CD007145. pub3. Available at: https://www.cochranelibrary. com/cdsr/doi/10.1002/14651858.CD007145.pub3/epdf/ abstract. Accessed September 08, 2020.

20. Shirazian T, Monteith S, Friedman F, Rebarber A. Lifestyle modification program decreases pregnancy weight gain in obese women. Am J Perinatol. 2010;27:411-4.

21. Olafsdottir AS, Skuladottir GV, Thorsdottir I, Hauksson 
A, Steingrimsdottir L. Maternal diet in early and late pregnancy in relation to weight gain. Int J Obes 2006;30:492-9.

22. Lagiou P, Tamimi RM, Mucci LA, Adami HO, Hsieh CC, Trichopoulos D. Diet during pregnancy in relation to maternal weight gain and birth size. Eur J Clin Nutr. 2004;58(2):231-7.

23. Institute of Medicine. Dietary reference intakes: the essential guide to nutrient requirements. National Academy Press: Washington DC; 2006.

24. American College of Obstetricians and Gynecologists. Exercise during pregnancy and the postpartum period. Clin Obstet Gynecol. 2003;46:496-9.

25. Gregg VH, Ferguson JE. Exercise in pregnancy. Clin Sports Med. 2017;36(4):741-52.

26. Hui A, Back L, Ludwig S, Gardiner P, Sevenhuysen G, Dean $\mathrm{H}$, et al. Effects of lifestyle intervention on dietary intake, physical activity level and gestational weight gain in pregnant women with different pre-pregnancy body mass index in a randomized control trial. BMC Pregnancy Childbirth. 2014;14:331-9.

27. Mottola M, Giroux I, Gratton R, Hammond JA, Hanley A, Harris S, et al. Nutrition and exercise prevent excess weight gain in overweight pregnant women. Med Sci Sports Exerc. 2010;42(2):265-72.

28. Guelinckx I, Devlieger R, Mullie P, Vansant G. Effect of lifestyle intervention on dietary habits, physical activity and gestational weight gain in obese pregnant women: a randomized controlled trial. Am J Clin Nutr. 2010;91:373-80.

29. Polley BA, Wing RR, Sims CJ. Randomized controlled trial to prevent excessive weight gain in pregnant women. Int J Obes Relat Metab Disord. 2002;26:1494-502.

30. Phelan S, Phipps M, Abrams B, Darroch F, Schaffner A, Wing R. Randomized trial of a behavioral intervention to prevent excessive gestational weight gain: the fit for delivery study. Am J Clin Nutr. 2011;93:772-9.

31. Huang T, Yeh C, Tsai Y. A diet and physical activity intervention for preventing weight retention among
Taiwanese childbearing women: a randomised controlled trial. Midwifery. 2011;27:257-64.

32. Asbee S, Jenkins T, Butler J, White J, Elliot M, Rutledge A. Preventing excessive weight gain during pregnancy through dietary and lifestyle counseling. Obstetrics Gynecology. 2009;113:305-12.

33. Savitz DA, Stein CR, Siega-Riz AM, Herring AH. Gestational weight gain and birth outcome in relation to prepregnancy body mass index and ethnicity. Ann Epidemiol. 2011;21:78-85.

34. Abdel-Aziz S, Hegazy I, Mohamed D, Abu EL Kasem M, Haga S. Effect of dietary counseling on preventing excessive weight gain during pregnancy. Public Health. 2018;154:172-81.

35. Margerison CE, Shrimali BP, Eskenazi B, Lahiff M, Lindquist AR, Abrams BF. Trimester of maternal gestational weight gain and offspring body weight at birth and age five. Matern Child Health J. 2012;16:121523.

36. Drehmer M, Duncan BB, Kac G, Schmidt MI. Association of second and third trimester weight gain in pregnancy with maternal and fetal outcomes. PLoS One. 2013;8(1):e54704. Available at: https://journals. plos.org/plosone/article/file?id=10.1371/journal. pone.0054704\&type=printable. Accessed June 28, 2020.

37. Davenport MH, Ruchat SM, Giroux I, Sopper MM, Mottola MF. Timing of excessive pregnancy-related weight gain and offspring adiposity at birth. Obstet Gynecol. 2013;122:255-61.

38. Jiang M, Gao H, Vinyes-Pares G, Yu K, Ma D, Qin X, et al. Association between breastfeeding duration and postpartum weight retention of lactating mothers: A meta-analysis of cohort studies. Clinical Nutrition. 2018;37:1224-31.

39. Devine CM, Bove CF, Olson CM, Continuity and change in women's weight orientations and lifestyle practices through pregnancy and the postpartum period: the influence of life course trajectories and transitional events. Social Science and Medicine. 2000;50:567-82. 